\title{
EFFICACY AND SAFETY OF LUMBAR ARTHROPLASTY IN DEGENERATIVE DISC DISEASE
}

\author{
EFICÁCIA E SEGURANÇA DA ARTROPLASTIA LOMBAR NA DOENÇA DO \\ DISCO DEGENERATIVO
}

\section{EFICACIA Y SEGURIDAD DE LA ARTROPLASTIA LUMBAR EN LA ENFERMEDAD DEGENERATIVA DE DISCO}

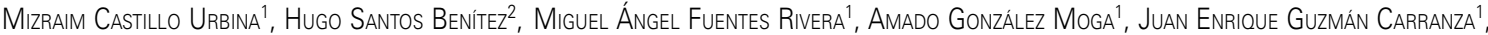 \\ Gabriel Huerta Hernández ${ }^{1}$ \\ 1. Centro Médico Issemym Ecatepec. Mexico.
}

2. Clínica Ruber Madrid, Spain.

\begin{abstract}
Objective: The objective of this longitudinal retrospective study is to assess the efficacy and safety of total lumbar disc replacement in patients with degenerative discopathy (L3-L4, L4-L5, L5-S1). Methods: One hundred and forty-three patients with low back pain, with or without radiculopathy, who met the radiographic criteria underwent anterior arthroplasty between 2000 and 2016. The Oswestry disability index (ODI), the visual analog scale (VAS), patient satisfaction, success criteria, disc height, and range of motion of the operated segment were evaluated preoperatively and at 3, 6, 12, and 24 months following surgery. Results: There were 50 men and 93 women, with an average age of 39.5 years, 13 patients (9\%) with previous discectomy. The arthroplasty was performed at level L5-S1 in 97 patients (67.8\%), at level L4-L5 in 45 patients (31.5\%), and at level L3-L4 in 1 patient. Between the preoperative period and 24 months following surgery, the ODI decreased by $53.86 \%$, the VAS for low back pain decreased by $63.83 \%$, and low back pain with radiculopathy decreased by $60.20 \%$, all statistically significant ( $\mathrm{p} \leq 0.5$ ). Eighty-two percent of the patients were completely satisfied and $18 \%$ were satisfied. There was an average increase in disc height of $12 \mathrm{~mm}(p<0.001)$. The range of motion of the affected segment increased by $4^{\circ}$ to $7^{\circ}$ after surgery $(p<0.004)$. Conclusions: Lumbar arthroplasty of a segment is recommended as an effective treatment for patients with degenerative disc disease with low back pain with or without a root component who meet the inclusion criteria. Level of Evidence III, Systematic review ${ }^{\boldsymbol{b}}$ of Level III studies.
\end{abstract}

Keywords: Lumbar region; Arthrodesis; Arthroplasty.

\section{RESUMO}

Objetivo: Para avaliar a eficácia e a segurança da reposição do disco lombar total em pacientes com discopatia degenerativa (L3-L4, L4-L5, L5-S1). Método: 143 pacientes com dor lombar com ou sem radiculopatia, os quais obedecem a critérios radiográficos, foram submetidos à artroplastia anterior entre 2000 e 2016. Avaliamos antes e após a cirurgia, três, seis, 12 e 24 meses, a Doença de Oswestry (ODI), escala analógico-visual (EVA), satisfação do paciente, critérios de sucesso, altura do disco e amplitude de movimento do segmento operado. Resultados: 50 homens e 93 mulheres. A idade foi de 39,5. 13 pacientes (9\%) com dissectomia prévia. Nível L5-S1 97 pacientes (67,8\%). Nível L4-L5 45 pacientes (31,5\%) e um paciente L3-L4 nível (0,6\%). A ODI entre o pré-operatório e os 24 meses pós-operatórios reduziu 53,86\%. O EVA na dor lombar reduziu 63,83\% nos 24 meses depois, em comparação com dor lombar, e pré-operatória com radiculopatia diminuiu 60,20\%, mudança estatisticamente significativa $(p \leq 0,5)$. $82 \%$ completamente satisfeitos e satisfeitos $18 \%$. A altura do disco aumentou $12 \mathrm{~mm}$ em média $(p<0.001)$. 0 movimento do segmento afetado aumentou de $4^{\circ}$ para $7^{\circ}$, após a cirurgia $(p<0,004)$. Conclusão: A artroplastia lombar de um segmento é recomendada como um tratamento eficaz para pacientes com doença degenerativa do disco, que atendem aos critérios de inclusão e lumbalgia sozinhos ou com um componente radicular. Nível de Evidência III: Revisão sistemática ${ }^{\boldsymbol{b}}$ de Estudos de Nível III.

Descritores: Região lombar; Artrodese; Artroplastia.

\section{RESUMEN}

Objetivo: Evaluar la eficacia y la seguridad del reemplazo total de disco lumbar en pacientes con discopatía degenerativa (L3-L4, L4-L5, L5-S1), mediante un estudio longitudinal retrospectivo. Métodos: Ciento cuarenta y tres pacientes con lumbalgia, con o sin radiculopatía, cumpliendo criterios radiográficos fueron sometidos a artroplastia por vía anterior entre 2000 y 2016 . Se evaluaron antes y tres, seis, 12 y 24 meses después de la cirugía el Índice de Discapacidad de Oswestry (ODI), escala analógica visual (EVA), satisfacción del paciente, criterios de éxito, altura discal y rango de movimiento del segmento operado. Resultados: Cincuenta hombres y 93 mujeres. Edad promedio 39,5, 13 pacientes (9\%) con discectomía previa. Nivel L5-S1 97 pacientes (67,8\%). Nivel L4-L5 45 pacientes (31,5\%) y un paciente nivel L3-L4 (0,6\%). El ODI entre el preoperatorio y 24 meses postoperatorios 
redujo 53,86\%. La EVA en la lumbalgia redujo 63,83\% 24 meses después en comparación con el preoperatorio y lumbalgia con radiculopatía disminuyó $60,20 \%$. Cambio estadísticamente significativo $(p \leq 0,5)$. El $82 \%$ completamente satisfecho y satisfecho 18\%. La altura discal aumentó $12 \mathrm{~mm}$ promedio ( $p$ 0,001). El movimiento del segmento afectado aumentó $4^{\circ}$ a $7^{\circ}$ después de la cirugía $(p<0,004)$. Conclusión: La artroplastia lumbar de un segmento se recomienda como tratamiento eficaz para pacientes con enfermedad degenerativa discal que cumplen con los criterios de inclusión y lumbalgia sola o con componente radicular. Nivel de Evidencia III; Revisión sistemáticab de Estudios de Nível III.

Descriptores: Región lumbar; Artrodesis; Artroplastia.

\section{INTRODUCTION}

Degenerative disc disease (DDD) or spondylosis has many causes: natural aging process (result of years of "wear and tear"), injury, trauma, obesity and so on. Spondylosis is a chronic degenerative condition of the spine that affects the vertebral bodies and the intervertebral discs, as well as the contents of the spinal canal (Figure 1).

The symptoms associated with degenerative lumbar spondylosis vary in terms of severity and have a relatively low correlation with the severity of the anatomical or radiographic changes. Surgical treatment can take the form of: a) decompression with or without fusion with the aim of relieving low back pain (with or without reference to symptoms in the leg, but with the dominant complaint of low back pain), or b) decompression of the nerve roots or cauda equina, with the aim of relieving neurogenic claudication. In general, fusion is considered if there is serious disc degeneration, poor alignment, or evidence of spinal instability. The debate over the acceptability of lumbar fusion as an effective and adequate method for treating low back pain in patients with degenerative lumbar spondylosis has been going on for more than 90 years. Satisfactory clinical outcomes reported vary widely and range from $16 \%$ to $95 \%$. $^{1-3}$ Dynamic stabilization is the new frontier in lumbar surgery. In an attempt to avoid the disadvantages inherent in rigid instrumentation and fusion, dynamic instrumentation systems have emerged, among them,

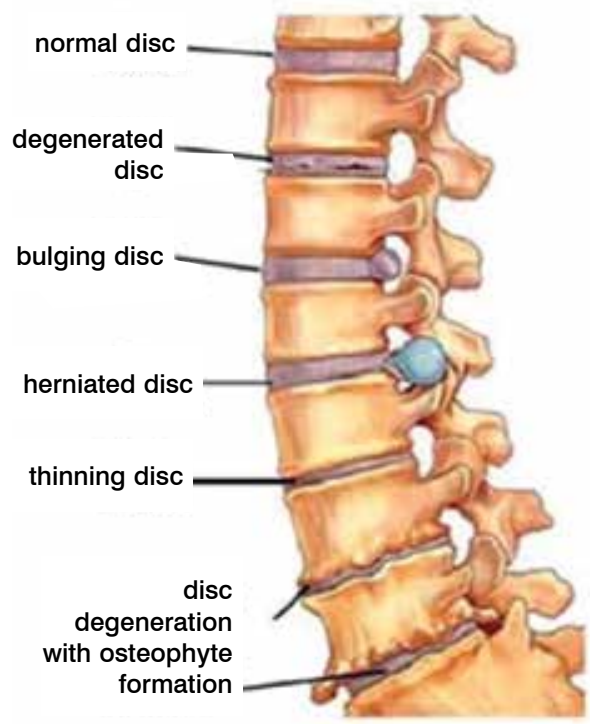

Figure 1. Changes associated with degenerative spinal spondylolysis. the Dynesys Dynamic Stabilization System (Zimmer Spine, Warsaw, IN) first used by Grob and Stoll. ${ }^{4,5}$ Other implants in development for the treatment of degenerative spinal disorders, without the creation of segmental fusion, include the X-Stop Interspinous Decompression System (St. Francis Medical Technologies, Inc., Alameda, CA). This implant has been available in Europe since June 2002. Zucherman and Lee ${ }^{6,7}$ headed up the studies using this system. Non-fusion techniques seek to provide stability while maintaining the mobility and function of the spine, eliminating the pain caused by the damaged intervertebral discs. ${ }^{8-10}$ Artificial discs have been used clinically in Europe since the late 1980s and rapidly became a viable treatment option during the 1990s. In 2004, the FDA approved the first implant for lumbar arthroplasty (SB Charité III, DePuy Spine, Raynham, MA) for use in the United States. ${ }^{11}$

\section{METHODS}

The retrospective data were collected from the clinical records of the patients who had undergone single-level lumbar arthroplasty, with or without a history of previous surgery for degenerative disc disease. These data were collected for patients who had been operated between 2000 and 2016. The devices used in all of them were the ProDisc- $L$ and the Activ- $L$ artificial discs. The patients ranged from 23 to 56 years of age. The indication for arthroplasty was rigorous and it was only performed in patients with chronic low back pain of discogenic origin with or without any root component in one of the L3-L4, L4-L5, or L5-S1 segments. All the patients had experienced symptoms for more than a year prior to the arthroplasty and failed conservative treatment during this period and none of those with a record of previous surgery had been operated on in the six months prior to the arthroplasty. These patients were selected based on the MRI findings, which included loss of disc height, low intensity in T2, changes in the endplates, and disc protrusion. No patients with osteoporosis, spinal stenosis, spondylolisthesis, chronic infections, metal allergies, pregnancy, severe facet joint arthropathy, multi-level degenerative changes, body mass index higher than 35 , or previously submitted to fusion technique were selected for arthroplasty (Table 1). All patients underwent a complete radiological study of the lumbosacral segment that included anterior-posterior and lateral (flexion and extension) view X-rays, CAT, and MRI. The latter two exams were used to estimate the grade of disc degeneration and the magnitude of the changes at the level of the facet joints (Figures 2, 3 and 4). The preoperative demographic data for all patients were collected retrospectively, in addition to the clinical parameters, which included whether there was only low back pain or low back pain with an associated radicular component, the frequency of the pain, the use of analgesic drugs; the Oswestry disability index (ODI) and visual analog scale (VAS) for pain scores, and the level of patient satisfaction (Table 2).

Table 1. Bertagnoli criteria for the ProDisc- $L$ disc prosthesis.

\begin{tabular}{c|c|c|c|c|c|c|c}
\hline Indications & Disc height & Facets & Adjacent level & Posterior elements & One level & Two levels & Three levels \\
\hline Excellent & $>4 \mathrm{~mm}$ & No OA & Without degeneration & Intact & $\sqrt{ }$ & & \\
\hline Good & $>4 \mathrm{~mm}$ & No OA & Minimal degeneration & $\begin{array}{c}\text { Minimal postlaminectomy } \\
\text { segmental instability }\end{array}$ & $\sqrt{ }$ & $\sqrt{ }$ & \\
\hline Borderline & $<4 \mathrm{~mm}$ & Primary OA & Minimal degeneration & Adjacent fusion & $\sqrt{ }$ & $\sqrt{ }$ & $\sqrt{ }$ \\
\hline Poor & $<4 \mathrm{~mm}$ & Secondary OA & Important degeneration & Instability & $\sqrt{ }$ & $\sqrt{ }$ & $\sqrt{ }$ \\
\hline
\end{tabular}




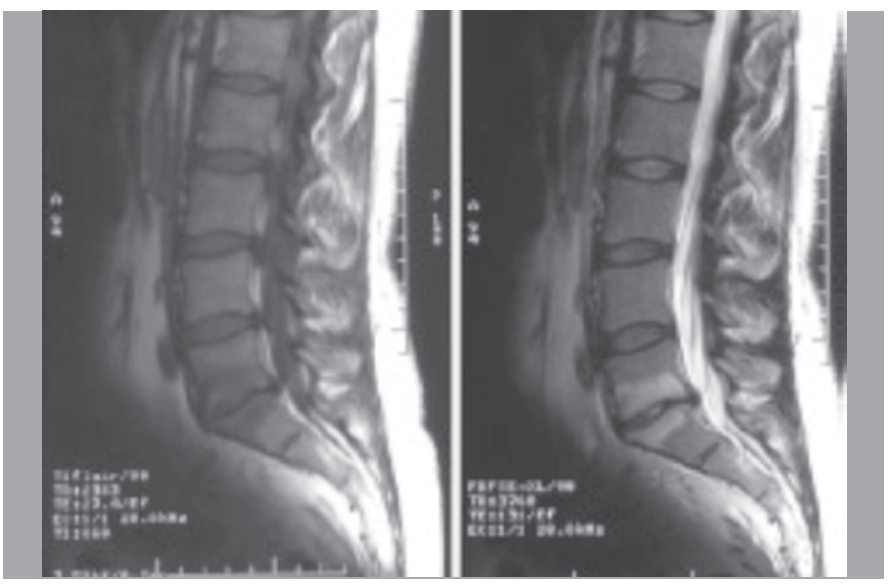

Figure 2. Sagittal T1 and T2 MRI images. On the left, hypointensity is observed around the L5-S1 space. On the right, the same patient in T2 with hyperintensity corresponding to Modic type I changes.
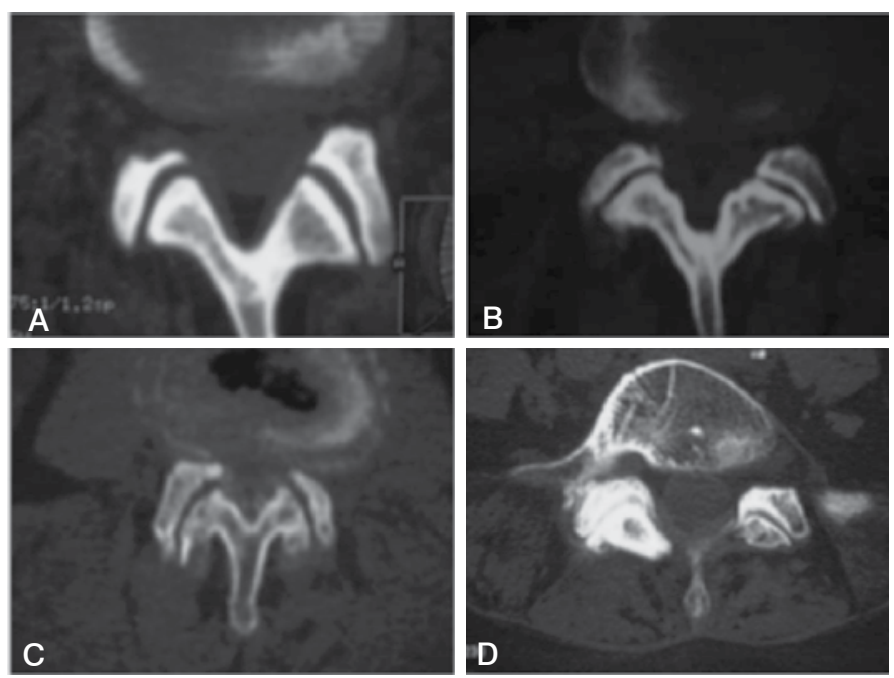

Figure 3. CT bone window showing the different grades of the facet joint arthropathy.

\section{Surgical technique}

The patient is placed on the operating table with both legs in abduction. Once the patient is properly positioned, the fluoroscope is brought to the surgical field and the appropriate marks are made in the abdominal region before asepsis and antisepsis. The incision, which can be either an infra-umbilical or an infra-supra-umbilical line, is then marked. Another more aesthetic variant is the transversal hypogastric incision (Figure 5). A mini-anterior left retroperitoneal approach is preferred. The anterior sheath of the rectus is opened and the rectus abdominis is retracted laterally. The retroperitoneal space is approached from below the arcuate line. The peritoneum is retracted medially. The great vessels are separated. Once the anterior disc is exposed and the level is verified, the midpoint of the disc space is marked in the AP plane under fluoroscopy. It is placed in the midline. The annulus is then incised and the two halves of the annulus are retracted laterally. After the anterior rectangular annulotomy, a complete discectomy is performed. The bone endplate should be preserved. The disc space should be distracted and mobilized to achieve an easy distraction. After the preparation of the endplate and the mobilization of the disc space, the implant test is performed. Both the height of the disc space and the intervertebral lordotic angles should be restored (Figure 6). Once the size and height of the disc and the angle of lordosis have been determined and the chiseling (only in cases of implants with keel) has been performed, the implant of the appropriate size is selected (two endplates and

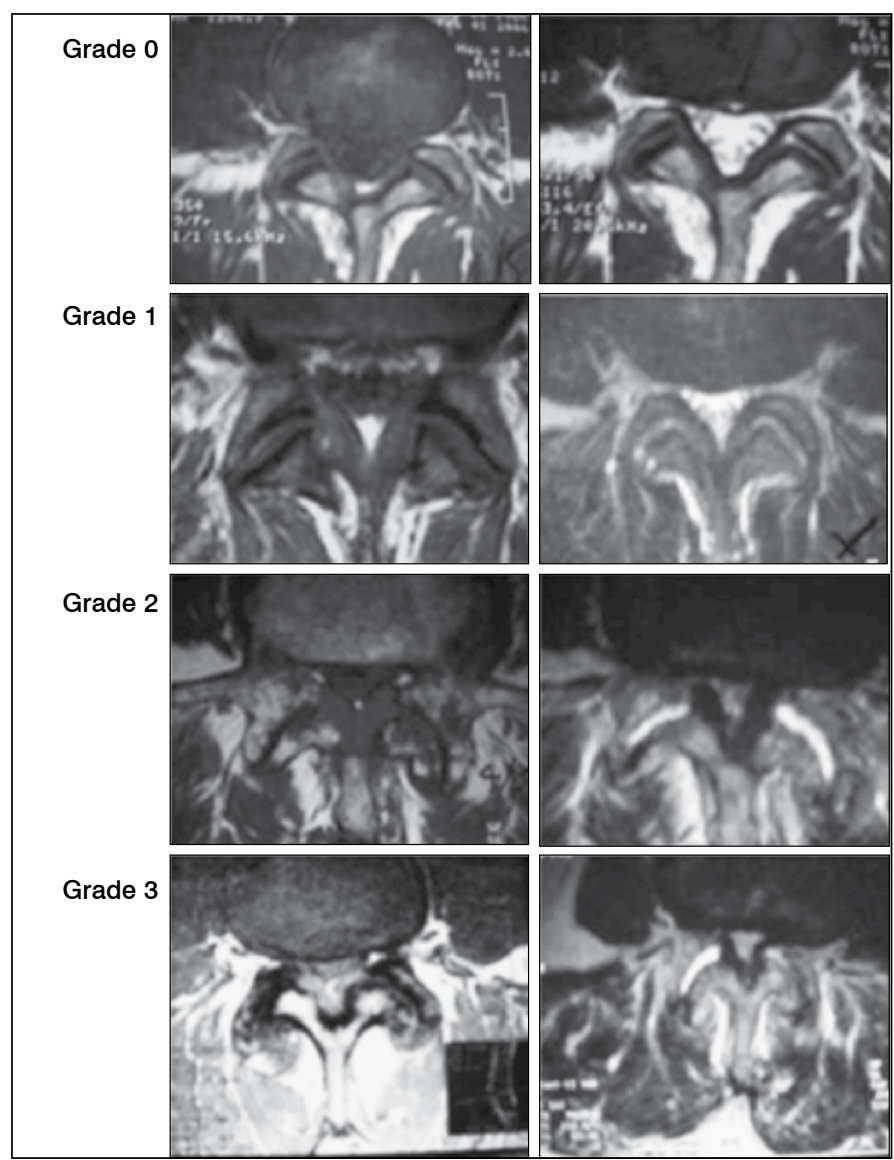

Figure 4. MRI T1, T2 that show the grades of facet joint arthropathy.

Table 2. Level of patient satisfaction.

\begin{tabular}{|c|}
\hline Completely satisfied \\
\hline - Without pain all day \\
\hline - Without impact that makes work and daily life activities impossible \\
\hline Satisfied \\
\hline $\begin{array}{l}\text { - Mild pain that does not require continuous medication that occurs no } \\
\text { more than once daily }\end{array}$ \\
\hline - Minimum impact to their work and daily life activities \\
\hline Unsatisfied \\
\hline - Pain occurring more than once a day requiring medication \\
\hline - Notable impact to daily life activities and their work \\
\hline
\end{tabular}

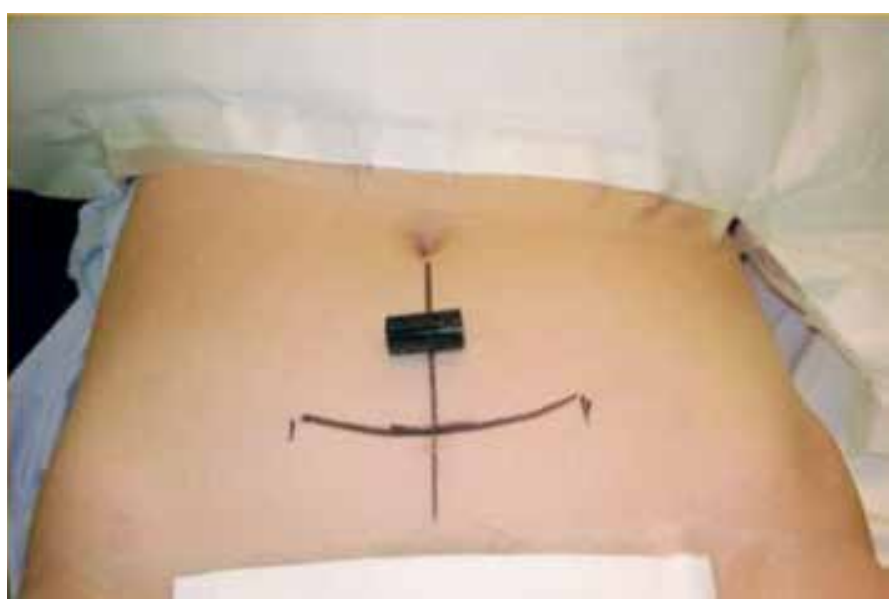

Figure 5. We have marked the most used incisions for approaching the L5-S1 space. 


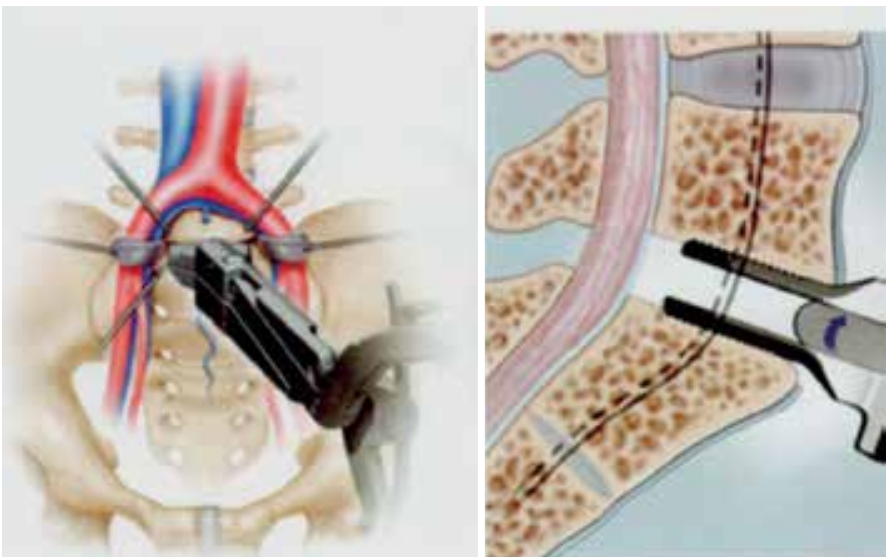

Figure 6. Diagram showing the use of tester before choosing the disc prosthesis.

a polyethylene insert) and placed. The implant is placed using fluoroscopic assistance in the AP and lateral planes. A final inspection of the implant, both visual and fluoroscopic, should be performed. A small drain is left and the skin is closed as aesthetically as possible. In the postoperative period, on the day of the surgery, patients wear a lightweight corset and walk. Most patients are ready for discharge on the first or second postoperative day.

All the patients were evaluated preoperatively and at three, six, 12, and 24 months following surgery. With the intention of collecting the greatest possible amount of information in each of these evaluations, data were collected for all the variables used internationally in this regard: 1) The evaluation of the functional results in terms of pain and disability was conducted using both the ODI and the VAS for lumbar pain and for lumbar pain with an associated root component; 2) To determine the frequency or duration of the pain without differentiating its location, the patients were classified into the three categories of without pain, with occasional pain, and with regular pain all day; 3) To determine the patient's level of satisfaction 24 months after surgical intervention, the guidelines described in Table 2 were followed; 4) The use of analgesic drugs was quantified; 5) The number of postoperative complications was collected in detail, dividing them into those related to the prosthesis and those related to the surgical approach; 6) The postoperative rate of return to work was quantified. In addition to describing the result of each of these variables in the different observation periods of the study and in order to deepen the elements of the efficacy and safety of lumbar arthroplasty, we tried to answer three main and several other collateral questions, all of investigative interest: 1) Whether the changes between the preoperative and three-months postoperative periods were significant; 2) If these were stable during the whole 24-month period analyzed; and 3) Whether these changes were maintained over time up to two years. In addition, it was necessary to know whether the outcomes might be worse in the patients with prior disc surgery, if there were differences between the patients whose initial symptoms were lumbar pain and those with lumbar pain with a root component, and whether the results could also be different in relation to the use of one versus another disc prosthesis and in relation to the L4-L5 versus L5-S1 space. To answer these questions the following analysis was conducted: 1) In order to determine the initial impact of the surgery, the preoperative ODI and VAS values were compared with the three-month values; 2) In the search for the elements of postoperative failure, the three-month and 24-month values of these same variables were compared; 3) To know the long-term impact of the surgery, a third analysis contrasted the same preoperative variables with the longest-term 24-month results; 4) To know the impact of prior surgery on the results, a comparison between the group of patients who had undergone prior surgery and that which had not been submitted to surgical intervention was conducted using the pre- and 24-month ODI values, as well as the rate of complications; 5) Using the preoperative ODI and the 24-month ODI as an indicator of long-term results, we compared the patients who used ProDisc- $L$ with those who used Activ- $L$ in a search for possible differences between the different prostheses used; 6) To know whether there were differences between the outcomes of patients who had a history of lumbar pain versus root pain, we compared their pre- and 24-month ODI values; 7) To know whether there were differences between the results of patients with the prosthesis placed in L4-L5 versus L5-S1, the pre- and 24-month ODI values were compared. Additionally, clinical success was defined taking the FDA criteria into account. This is achieved when the following four criteria are met: 1) an improvement of 15 points in the ODI; 2) no complication related to the prosthesis; 3) no major complication related to the approach (in which there is blood loss greater than $1500 \mathrm{cc}$ ); and 4) no neurological changes occurred.

\section{Follow-up and radiographical evaluation}

In the postoperative period, lumbosacral X-ray studies were performed in AP and lateral views in neutral, flexion, and extension positions. With these views, detailed measurements of the height of the affected and adjacent intervertebral spaces were taken, as well as of the angular movement of the intervertebral disc. The pre- and postoperative measurements were compared.

\section{Statistical analysis}

We used a paired comparison analysis $(p<0.05)$ to contrast the VAS for lumbar pain with a root component, VAS for lumbar pain only, and ODI values before the surgery and at three and 24 months after the surgery. To determine whether there were differences between the three- and 24-month postoperative values of the three variables studied, a multiple comparison of the mean values at three, six, 12, and 24 months was made using Analysis of Variance. The normality of the data was proven using the normalized skewness and kurtosis values and when they exceeded 2.0, the Kruskal-Wallis test was used to compare the medians. The Cochram test was used to determine the homogeneity of the variances. The results obtained for the data pairs with surgery and without surgery before and at 24 months, Prodisc-L and Activ- $L$ before the surgery and 24 months after the surgery, and level L4-L5 vs. L5-S1 before the surgery and 24 months after the surgery were compared using the Student's t test for $p \leq 0.05$. The analyses were conducted using the Statgraphics 5 statistical program package.

\section{RESULTS}

Surgery was performed in 143 patients, 50 of whom were men and 93 of whom were women. The average age for both sexes was 39.5 years. The average duration of pain prior to surgery was 62 months, ranging from 12 to 200 months. Thirteen patients (9\%) had previously undergone posterior approach discectomy at the same site where the arthroplasty was placed and none underwent surgical intervention at the adjacent sites. The predominant level in the patients who received the arthroplasty was L5-S1 with 97 patients $(67.8 \%)$, followed by L4-L5 with 45 patients $(31.5 \%)$, and only one patient at level L3-L4 (0.6\%). The average surgical time was 3.21 hours, ranging from 1 hour and 30 minutes to 5 hours and 30 minutes. The average blood loss was $90 \mathrm{ml}$ (50-300). The average hospital stay was 5.6 days ranging from 3 to 8 days (Table 3 ).

Table 3 Demographic patient characteristics.

\begin{tabular}{c|c}
\hline Characteristics & Average, Range, \% \\
\hline Age & 38.5 years (23-52) \\
\hline \multirow{2}{*}{ Sex } & $18 \mathrm{M}$ \\
\cline { 2 - 2 } & $62 \mathrm{~F}$ \\
\hline Duration of pain & 62 months (12-200) \\
\hline Lumbalgia & $41 \%$ \\
\hline Lumbalgia with bilateral root component & $5 \%$ \\
\hline Lumbalgia with right root component & $15 \%$ \\
\hline Lumbalgia with left root component & $34 \%$ \\
\hline
\end{tabular}




\section{Clinical results}

The Oswestry disability index decreased from $46.19 \%$ in the preoperative period to $21.10 \%$ at three months following surgery. The ODI values in the controls performed at six, 12, and 24 months were similar to those at 3 months following surgery (Figure 7 ). This means that the most notable change occurred immediately following surgical intervention. If we evaluate this change in the ODI between the preoperative period and the latest period of these patients observation at 24 months, we can conclude that an average reduction in the ODI of $53.86 \%$ was achieved. The value of the visual analog scale for the lumbar pain component decreased from 5.64 preoperatively to 1.81 at three months following surgery, however like the ODI, in the other evaluations at six, 12, and 24 months the values were similar to the three-month ones (Figure 8 and Table 4). The average decrease in the VAS for pure lumbar pain at 24 months compared to the preoperative value was $63.83 \%$. The VAS for lumbar pain with a root component also experienced a reduction from 5.98 to 2.14. The six-, 12-, and 24-month evaluations behaved similarly to the previous one and the mean value of this variable between the postoperative period and the 24-month follow-up decreased by $60.20 \%$ (Figure 8). The results of the paired comparison between the VAS for lumbar pain with a root component before the surgery and at three months showed that the null hypothesis that proposed that the average of the differences of the observations is equal to 0.0 is rejected ( $t=12.881 ; P=0.0$ for $\alpha=0.05)$. Similar results were obtained with the comparison against 24 months $(t=11.355 ; \mathrm{P}=$ 0.0 for $\alpha=0.05$ ). The results indicate that there is a significant difference between the VAS for lumbar pain with a root component values

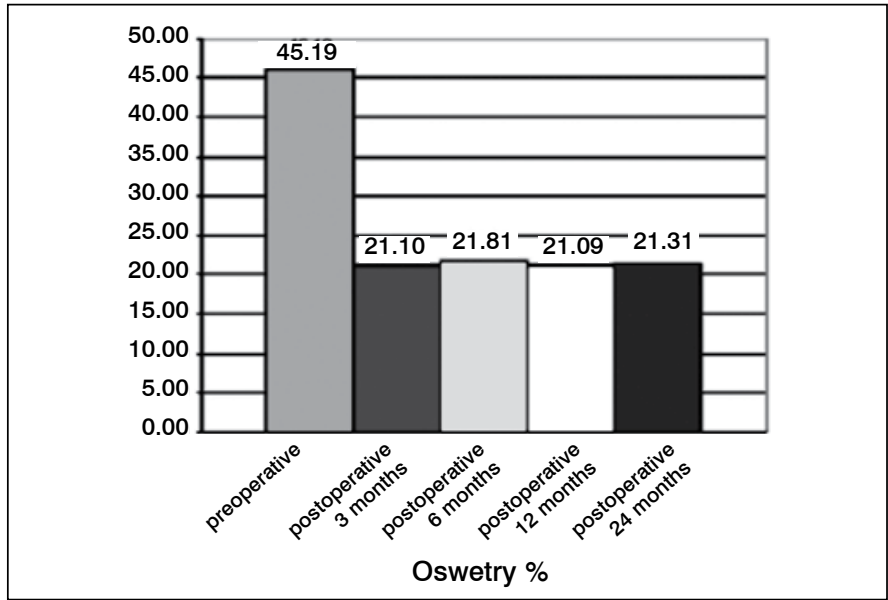

Figure 7. This graph displays the pre- and postoperative results in all the controls of the Oswestry disability index (ODI).

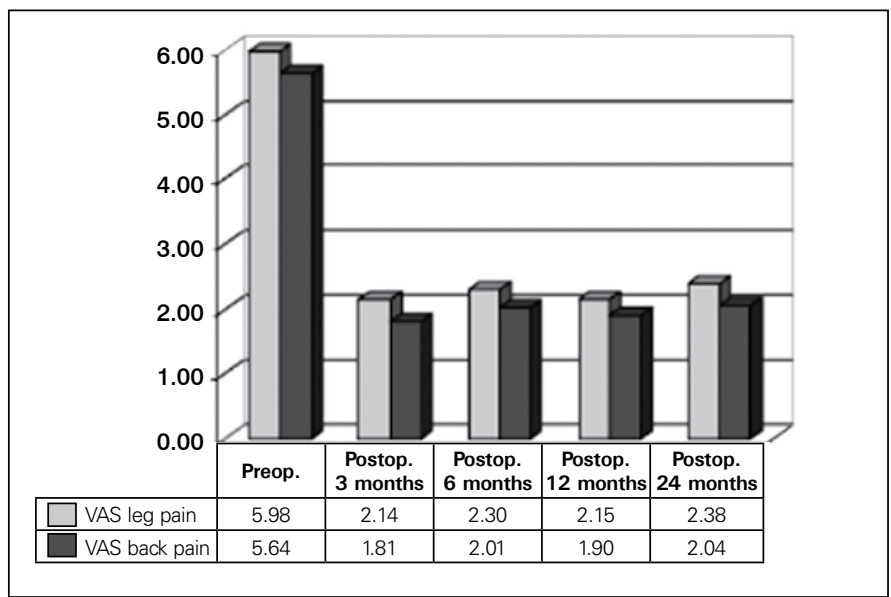

Figure 8. This graph displays the pre- and postoperative results in all the controls of the of the visual analog scale for pain (VAS) for lumbar pain and root pain. before and after the surgery at three and at 24 months. The Analysis of Variance performed to confirm the existence of significant differences in the VAS for lumbar pain with a root component at three, six, 12, and 24 months can be observed in Table 5, which shows that no significant differences were found for the mean values of the variable at the four times measured for 95\% confidence. For this variables, the normalized skewness and kurtosis values exceeded the 2.0 limit, so the Kruskal-Wallis test was also executed to compare the medians and the results showed that there were no significant differences between the medians of the VAS for lumbar pain with a root component at the four times measured for 95\% confidence $(t=1.168 ; P=0.760)$. The Cochram test showed homogeneity between the Variances $(C=0.274 ; P=0.944)$. For the VAS for lumbar pain the paired comparison yielded results similar to those of the VAS for radicular pain, both at three months $(t=16.7 ; \mathrm{P}=$ 0.0 for $\alpha=0.05)$ and at 24 months $(t=16.5$; $P=0.0$ for $\alpha=0.05)$, rejecting the null hypothesis that the average of the differences in the observation is equal to 0.0 , so it can be considered that there is a significant difference for the VAS for lumbar pain before and after the surgery. The results of the Analysis of Variances can be seen in Table 6, where it can be observed that there were no significant differences for the mean values of the variable in the four times measured (three, six, 12, and 24 months) for 95\% confidence. Likewise, the Cochram test showed homogeneity between the Variances $(C=0.270 ; P=1.0)$. The paired comparison performed for the variable ODI before and at three and 24 months following the surgery yielded the same results for the VAS for lumbar pain with a root component and VAS for lumbar pain variables, rejecting the null hypothesis that the average of the differences of the observations is equal to 0.0 ( $t=15.47 ; P=0.0$ for $\alpha=0.05$ ) for the two comparisons, so that it can be considered that significant differences exist between the mean values of this variable before the surgery and at three and 24 months afterwards. The Analysis of Variances for the ODI in the four times measured (three, six, 12, and 24 months) for 95\% confidence showed that for this variable the normalized skewness and kurtosis values exceeded the limit of 2.0, so the Kruskal-Wallis test was performed the compare the medians. The ANOVA results are shown in Table 7 where it can be seen that there are no significant differences.

Twenty-four months following surgery, $93.1 \%$ of the patients were in the category of no pain or occasional pain in the lumbar region (Table 8). Prior to surgery, $43.8 \%$ of the patients had lumbar pain with a root component, while at 24 months it was reported in only $7.8 \%$ of the patients (Table 9 ).

Table 4. Visual analog scale and Oswestry disability index values $(n=143)$

\begin{tabular}{c|c|c|c}
\hline & $\begin{array}{c}\text { VAS for lumbar pain } \\
\text { with root component }\end{array}$ & $\begin{array}{c}\text { VAS for lumbar } \\
\text { pain }\end{array}$ & ODI \\
\hline Preoperative & $6.0(3.0)$ & $5.6(1.7)$ & $46.1(13.0)$ \\
\hline 3 months & $2.1(1.6)$ & $1.8(1.2)$ & $21.1(5.8)$ \\
\hline 6 months & $2.3(1.6)$ & $2.0(1.2)$ & $21.8(5.8)$ \\
\hline 12 months & $2.2(1.5)$ & $1.9(1.1)$ & $21.1(6.1)$ \\
\hline 24 months & $2.4(1.5)$ & $2.0(1.1)$ & $21.3(5.8)$ \\
\hline
\end{tabular}

Mean (Standard Deviation) Oswestry disability index (\%).

Table 5. ANOVA for VAS lumbar pain with root component results.

\begin{tabular}{c|c|c|c|c|c}
\hline Source of Variance & $\begin{array}{c}\text { Sum of } \\
\text { Squares }\end{array}$ & DF & $\begin{array}{c}\text { Mean } \\
\text { Square }\end{array}$ & F statistic & P value \\
\hline Between time & 3.23 & 3 & 1.07 & 0.43 & 0.72 \\
\hline Within time & 783.24 & 316 & 2.47 & & \\
\hline Total & 786.47 & 319 & & & \\
\hline
\end{tabular}

Table 6. ANOVA for VAS lumbar pain results.

\begin{tabular}{c|c|c|c|c|c}
\hline Source of Variance & $\begin{array}{c}\text { Sum of } \\
\text { Squares }\end{array}$ & DF & $\begin{array}{c}\text { Mean } \\
\text { Square }\end{array}$ & F statistic & P value \\
\hline Between time & 2.60 & 3 & 0.86 & 0.64 & 0.58 \\
\hline Within time & 429.26 & 316 & 1.35 & & \\
\hline Total & 431.86 & 319 & & & \\
\hline
\end{tabular}


Table 7. ANOVA for ODI results

\begin{tabular}{c|c|c|c|c|c}
\hline Source of Variance & $\begin{array}{c}\text { Sum of } \\
\text { Squares }\end{array}$ & DF & $\begin{array}{c}\text { Mean } \\
\text { Square }\end{array}$ & F statistic & P value \\
\hline Between time & 27.5 & 3 & 9.19 & 0.26 & 0.856 \\
\hline Within time & 11317.0 & 316 & 35.81 & & \\
\hline Total & 11344.5 & 319 & & & \\
\hline
\end{tabular}

Table 8. Lumbar pain (\%).

\begin{tabular}{c|c|c}
\hline & Preop. & 24 months \\
\hline No pain & 0 & 33 \\
\hline Occasional pain & 14.2 & 60.1 \\
\hline Regular pain & 85.8 & 6.9 \\
\hline
\end{tabular}

Table 9. Lumbar pain with root component (\%)

\begin{tabular}{c|c|c}
\hline & Preop. & 24 months \\
\hline No pain & 12.8 & 61.3 \\
\hline Occasional pain & 43.4 & 30.9 \\
\hline Regular pain & 43.8 & 7.9 \\
\hline
\end{tabular}

\section{Radiographical analyses}

The average discal height value, measured preoperatively, was $4 \mathrm{~mm}$. In 93 patients, a loss of at least $65 \%$ of disc height was observed as compared to the adjacent level. In the rest of the patients, only minimum to moderate disc height loss was observed, but they presented disc herniation with an extrusion component. Following surgery, the disc height increased to an average of $12 \mathrm{~mm}$ $(p<0.001)$ (Figure 9). The movement of the affected disc increased from 4 degrees to 7 degrees on average after the surgery $(p<0.004)$ (Figure 10). The height of the adjacent disc did not change. There were no cases of subsidence.

\section{Complications}

There were no complications related to the prosthesis. Complications related to the approach occurred in 11 patients, who represented $7.69 \%$ of the sample. Three patients had tears to the peritoneum that were sutured during the same operation without any repercussion to the patients. Two patients had retrograde ejaculation but recovered spontaneously during the period of 5 to 7 months following surgery. As can be seen, all the complications were minor, were resolved with medical treatment and without the need for additional surgical intervention, and there were no resulting permanent deficits.

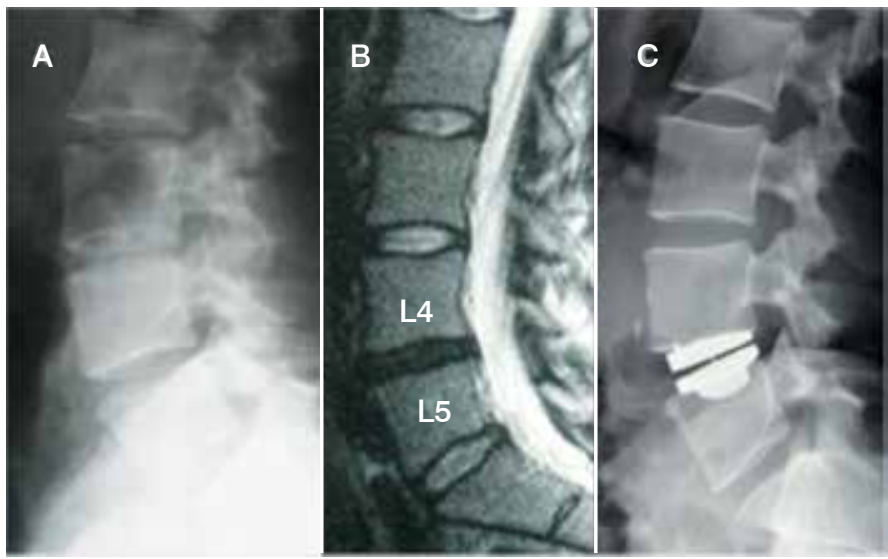

Figure 9. A: preoperative lumbosacral X-ray of one of the patients; B: Sagittal MRI in T2 in which hypointensity and loss of height of the L4-L5 disc, which was operated, are observed; C: LSX-ray in which the placement of the implant and the reestoration of the height of the discal segment can be seen.

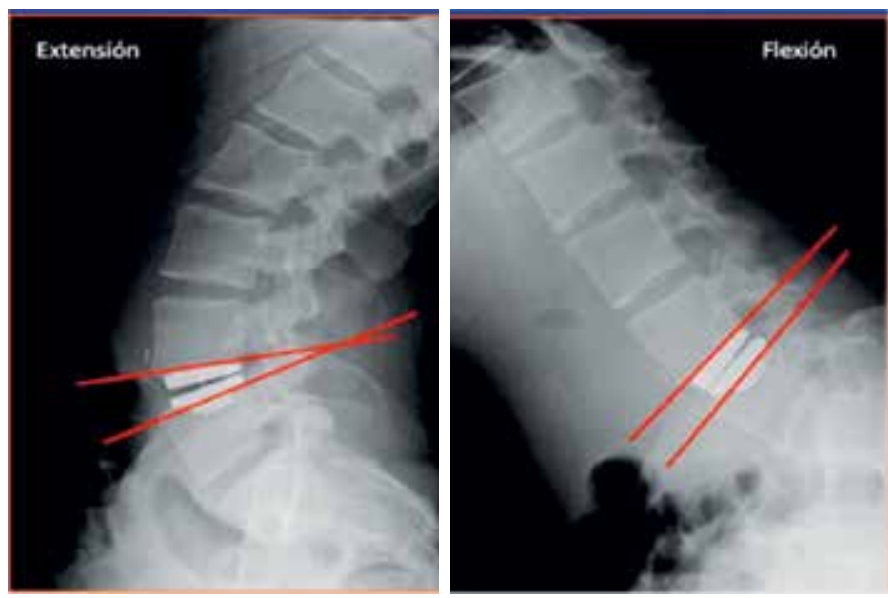

Figure 10. Lumbosacral X-ray which shows the method used by the author to measure the range of motion after placement of the prosthesis.

\section{DISCUSSION}

The use of total disc arthroplasty has been under investigation for approximately 25 years. ${ }^{13-21}$ It has been proposed as a substitute for spinal fusion to treat chronic low back pain while preserving vertebral movement in the operated level and protecting the adjacent levels from future degenerative changes. Although in a general sense their clinical results are not considerably different, many of these studies present methodological differences, especially in terms of the type of study, the levels of evidence that they provide, the type of prosthesis they explore, the patient follow-up periods, and the tools used to measure the results. This was very clearly demonstrated in a meta-analysis conducted by Michael R. Zindrick in 2008. The follow-up periods reported in this table are quite variable and one factor among others that can influence this is the fact that there are different disc prostheses in these studies and they did not all emerge and begin their clinical application during the same period, which implies differences in the field. Some have a much shorter period of commercial use than others that provide longer observation periods. There are several studies in the literature with long follow-up periods and most of them, which is logical, were conducted with the Charite I prosthesis, the first to be used in 1984, and also with the Charite III, of which the first clinical experience in lumbar arthroplasty was reported in 1994. Lemaire et al. published a study with 10 years of follow-up in 100 patients using Charite. They reported excellent or good results in $90 \%$ of cases. Degeneration at the adjacent level was only observed in $2 \%$ of cases and the range of the degeneration of the facet joint remained relatively minimal at $11 \%$. In 2006, Putzier et al. published a second long-term study, reporting 17 years of follow-up. They found spontaneous ankylosis in $60 \%$ of the patients, suggesting the need for studies of equal length to clarify the long-term efficacy of arthroplasty. This study basically failed due to its weak statistical analysis, the possibility of much bias in the patient selection criteria, and the study design.

\section{CONCLUSIONS}

We recommend lumbar arthroplasty at a single level as an effective and safe procedure for patients with degenerative disc disease who meet the inclusion criteria and present symptoms of either pure low back pain or low back pain with a root component. The benefits were significant at three months and remained until 24 months after total disc replacement. It seems there were no differences between the results of patients with a history of previous surgery and those without, nor between patients with chronic low back pain and those with an associated root component. Neither did the two prostheses used or the level operated (L4-L5 versus L5-S1) influence the results. No complications were related to the implanted device. Careful and 
appropriate patient selection is essential in the planning of an optimum surgical outcome.

\section{ACKNOWLEDGEMENTS}

To the Clínica Ruber de Madrid, Spain, to Dr. Hugo A. Santos Benítez, and to the ISSEMYM medical center for allowing us to work in an adequate manner and for giving us the opportunity to count on the resources for our study. To our patients for their trust.

All authors declare no potential conflict of interest related to this article.

CONTRIBUTION OF THE AUTHORS: Each author made significant individual contributions to the manuscript. MCU (0000-0003-3936-5309)* and HSB (0000-0002-4106-5527)* were the main contributors to the preparation of the manuscript. MCU, HSB, MAF (0000-0003-0833-1245)*, and AMG $(0000-0003-1745-0334)^{\star}$ performed the surgeries, followed-up with patients, and collected the clinical data. EG $(0000-0002-8793-7538)^{\star}$ and GH (00000001-7049-2993)* evaluated the statistical analysis data. MCU and HSB conducted the bibliographical research, reviewed the manuscript, and contributed to the intellectual concept of the study. *ORCID (Open Researcher and Contributor ID).

\section{REFERENCES}

1. Ray CD. The artificial Disc: introduction, history, and socioeconomics. In: Weinstein, JN ed. Clinical Efficacy and Outcome in the Diagnosis and Treatment of Low Back Pain. New York: Raven; 1992. p. 205-225.

2. White AA. Panjabi MM. Clinical Biomechanics of the Spine. Philadelphia: Lippincott Williams Wilkins; 1990.

3. Pope MH. Disc biomechanics and herniation. In: Gunzburg R, Szapalski M, eds. Lumbar Disc Herniation. Philadelphia: Lippincott Williams \& Wilkins. 2002. p.3-21.

4. Grob D, Benini A, Junge A, Mannion AF. Clinical experience with the Dynesys semirigid fixation system for the lumbar spine: surgical and patient-oriented outcome in 50 cases after an average of 2 years. Spine (Phila Pa 1976). 2005:30(3):324-31.

5. Stoll TM, Dubois G, Schwazenbach $O$. The dynamic neutralization system for the spine: a multi-center study of a novel nonfusion system. EurSpine J. 2002;I I(Suppl 2):S170-8.

6. Zucherman JF, Hsu KY, Hartien CA, Mehalic TF, Implicito DA, Martin MJ. et al. A prospective randomized multi-center study for the treatment of lumbar spinal stenosis with the $X$ STOP interspinous implant: I "year results. Eur Spine J. 2004;13(1):22-31.

7. Lee F, Hida K, Sek T. Iwasaki Y. Minoru A. An interspinous process distractor (X STOP) for lumbar spinal stenosis in elderly patients: preliminary experiences in 10 consecutive cases. J Spinal Disord Tech. 2004:17(1):72-7.

8. Traynelis VC. Spinal arthroplasty. Neurosurg Focus. 2002;13(2):E10

9. Bao QB, Yuan HA. Artificial disk technology. Neurosurg Focus. 2000;9(4):e14.

10. Le H, Thongtrangan I, Kim DH. Historical review of cervical arthroplasty. Neurosurg Focus. $2004 ; 17(3):$ : 1 .
11. Administration USFD. Charite Artificial Disc (P04000ó) Approval Letter IDePuy Spine, Inc.l, 2004. Available at: http://www.fda.gov/cdrh/pdf4/p0400óLpdf. Accessed May 26, 2005.

12. Fairbank JC, Couper J, Davies JB, O'Brien JP. The Oswestry low back pain disability questionnaire. Physiotherapy. 1980;66(8):271-3.

13. Fraser RD, Ross ER, Lowery GL, Freeman BL, Dolan M. AcroFlex design and results. Spine J. 2004;4(6 Suppl):245S-51S.

14. Steffee AD. Artificial spinal disk. European patent 0392076. October 17,1990.

15. Steffee AD. Artificial disk. United States patent 5071437. December 10, 199I.

16. Steffee AD. The Steffee artificial disk. In: Weinstein IN, ed. Clinical Efficacy and Outcome in the Diagnosis and Treatment of Low Back Pain. New York: Raven; 1992.

17. Enker P, Steffee A, McMillin C, Keppler L, Biscup R, Miller S. Artificial disk replacement: preliminary report with a 3-year minimum follow up. Spine (Phila Pa 1976). 1993;/8(8): 106|-70.

18. Serhan H, Kuras J, McMillin C, Persenaire M. Spinal disk prosthesis. World patent 99/20209. 1999.

19. Fraser RD, Ross ER, Lowery GL, Steffe AD. Spinal disk. United States patent 6139579. October 3 I, 2000.

20. Cunningham BW, Lowery GL, Serhan HA, Dimiytriev AE, Orbegoso CM, Mcafee PC, et al. Total disk replacement arthroplasty using the AcroFlex lumbar disk, a non-human primate model. Eur Spine J. 2002;11 (Suppl 2):S115-23.

21. BüttnerJanz K, Hochschuler SH, McAfee PC. The Artificial Disc, Ist ed. Berlin: SpringerVerlag; 2003. 